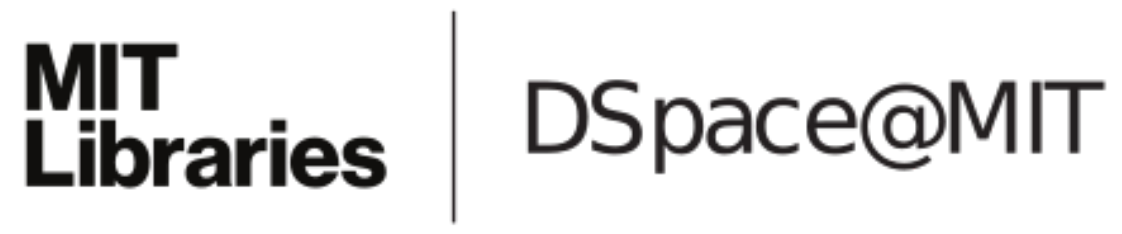

\author{
MIT Open Access Articles
}

\begin{abstract}
Efficient, balanced, transmission line RF circuits by back propagation of common impedance nodes
\end{abstract}

The MIT Faculty has made this article openly available. Please share how this access benefits you. Your story matters.

Citation: Markhasin, Evgeny, Jianping Hu, Yongchao Su, Judith Herzfeld, and Robert G. Griffin. “Efficient, Balanced, Transmission Line RF Circuits by Back Propagation of Common Impedance Nodes." Journal of Magnetic Resonance 231 (June 2013): 32-38.

As Published: http://dx.doi.org/10.1016/j.jmr.2013.02.017

Publisher: Elsevier

Persistent URL: http://hdl.handle.net/1721.1/103904

Version: Author's final manuscript: final author's manuscript post peer review, without publisher's formatting or copy editing

Terms of use: Creative Commons Attribution-NonCommercial-NoDerivs License 


\section{Efficient, balanced, transmission line RF circuits by back propagation of common impedance nodes}

Evgeny Markhasin ${ }^{\mathrm{a}}$, Jianping Hu${ }^{\mathrm{b}}$, Yongchao Su${ }^{\mathrm{a}}$, Judith Herzfeld ${ }^{\mathrm{b}}$, and Robert G. Griffin ${ }^{\mathrm{a}}{ }^{*}$ ${ }^{a}$ Francis Bitter Magnet Laboratory, Department of Chemistry, Massachusetts Institute of Technology, Cambridge, MA 02139, USA



\section{Abstract}

We present a new, efficient strategy for designing fully balanced transmission line RF circuits for solid state NMR probes based on back propagation of common impedance nodes (BPCIN). In this approach, the impedance node phenomenon is the sole means of achieving mutual RF isolation and balance in all RF channels. BPCIN is illustrated using a custom double resonance $3.2 \mathrm{~mm}$ MAS probe operating at $500 \mathrm{MHz}\left({ }^{1} \mathrm{H}\right)$ and $125 \mathrm{MHz}\left({ }^{13} \mathrm{C}\right)$. When fully optimized, the probe is capable of producing high homogeneity $\left(810^{\circ} / 90^{\circ}\right.$ ratios of $86 \%$ and $89 \%$ for ${ }^{1} \mathrm{H}$ and ${ }^{13} \mathrm{C}$, respectively) and high efficiency $\left(\gamma B_{1}=100 \mathrm{kHz}\right.$ for ${ }^{1} \mathrm{H}$ and ${ }^{13} \mathrm{C}$ at $70 \mathrm{~W}$ and $180 \mathrm{~W}$ of RF input, respectively; up to $360 \mathrm{kHz}$ for ${ }^{1} \mathrm{H}$ ). The probe's performance is illustrated by 2D MAS correlation spectra of microcrystals of the tripeptide N-f-MLF-OH and hydrated amyloid fibrils of the protein PI3-SH3.

\section{Keywords}

MAS NMR; RF circuit; Isolation; Balance; Common impedance node

\section{Introduction}

Due to multiple advances in magic angle spinning (MAS) NMR in the last two decades, it is rapidly becoming accepted as a powerful and versatile tool for many fields and particularly structural biology [1-15]. These advances are the result of progress in both MAS methodology $[1,7,16,17]$ and instrumentation [18-21].

Contemporary biological MAS applications set stringent, often contradictory, requirements for NMR probes, with the most important subsystem being the radio-frequency (RF) circuit. Critical features include RF efficiency, RF field homogeneity, and RF heating at high $\left({ }^{1} \mathrm{H}\right)$ and low $\left({ }^{13} \mathrm{C}\right.$ and $\left.{ }^{15} \mathrm{~N}\right)$ frequencies, as well as the robustness and stability. In addition, advanced applications, such cryogenic MAS and dynamic nuclear polarization (DNP) enhanced NMR, require that the probe RF circuit function over a wide range of temperatures [22-31].

An NMR probe circuit comprises a resonator, which houses the sample, and a tuning/ matching network. Different types of commonly used NMR resonators, each having certain

(C) 2013 Elsevier Inc. All rights reserved.

"Corresponding author. rgg@ @it.edu.

Disclosure statement Brandeis University holds a patent for the circuit design described in this paper [37]. 
strengths and weaknesses, are reviewed elsewhere [18]. A suitable tuning/matching network not only tunes the resonator, but can also compensate for certain weaknesses.

Tuning/matching circuits may provide common mode (Fig. 1a) or balanced (Fig. 1b) input, with a balanced design providing a number of advantages over common mode design [3235]. These include improved RF field homogeneity [32] and power efficiency [36]. While the former is generally important for multiple pulse and recoupling experiments [32], the latter is particularly crucial for experiments on biological samples, which are often sensitive to RF heating caused by ${ }^{1} \mathrm{H}$ decoupling. We have recently introduced a novel balanced transmission line RF circuit design [33,34,37]. Here we present results from a fully balanced ${ }^{13} \mathrm{C} /{ }^{1} \mathrm{H}$ transmission line probe and discuss the underlying theory of the circuit design.

\section{RF circuit design and implementation}

\subsection{Circuit overview}

The schematic in Fig. 2a illustrates a double resonance, balanced RF circuit design, and Fig. $2 \mathrm{~b}$ shows a block diagram of the same circuit. The circuit can be divided into two parts connected to opposite ends of the solenoid resonator. The combination of the left "tuning/ matching" side and the right "balun" side results in a completely balanced output to the sample coil (Fig. 2b). On each side, individual RF channels are connected at common impedance nodes (black dots in Fig. 2), which assure mutual isolation without insertion of lossy RF traps (as discussed below).

\subsection{Circuit design based on impedance nodes}

A key role of the tuning/matching network in a multi-channel RF circuit is to maximize channel independence and limit RF losses by means of isolation. Traditional isolation elements have included lumped RF traps [38], transmission line based RF traps [39,40] and their lumped analogs [41]. Sometime ago McKay [42] used a ${ }^{1} \mathrm{H}$ impedance node as an isolation element in a transmission line probe. Here we demonstrate that complete and efficient isolation between the RF channels can be achieved using impedance nodes as the only isolation elements.

Fig. 3a shows a parallel combination of two impedance elements with impedance $Z_{p}$ at the junction point

$$
Z_{p}=\frac{Z_{1} \cdot Z_{2}}{Z_{1}+Z_{2}}
$$

The incoming signal (gray arrows in Fig. 3a) will split at the junction point in proportion to the electrical admittance of the individual branches. If one of the elements in a parallel combination is a short (Fig. 3b), the impedance at the junction point will also be zero and the incoming signal will flow exclusively through the shorted branch. Similarly, if one impedance element in a parallel combination is much smaller than the others (Fig. 3c), then Eq. (1) can be simplified as

$$
Z_{p}=\frac{Z_{1} \cdot Z_{2}}{Z_{1}+Z_{2}}=\frac{Z_{1} \cdot Z_{2}}{Z_{1}}
$$

Although the incoming signal will split at the junction point, most of the signal will flow through the branch that has the smallest impedance. 
If the incoming signal is an RF signal, it is possible to adjust (tune) the impedance of a branch such that the condition in Fig. $3 \mathrm{c}$ is only fulfilled in a narrow frequency band (Fig. 3d). In that case, the circuit will have an impedance node at the junction point at that frequency, i.e. a point at which impedance with respect to ground is very small at that frequency. For incoming signals within that band, the behavior of the circuit will be similar to that in Fig. 3c, while for other frequencies it will be similar to that in Fig. 3a. If the incoming signal is a superposition of several components with different frequencies, the circuit will behave with respect to each component as if it was the only component.

A branch that tunes an impedance node at a given frequency behaves like ground at that frequency. It is, thus, convenient to say that an impedance node pulls the signal (in the band to which the node is tuned) through the corresponding tuned branch.

It is also possible to tune different branches to different frequencies. In that case, the junction point will have a common impedance node, i.e. a point where an impedance node occurs simultaneously at several different frequencies, and a composite signal will split at the junction point so that each component will predominantly flow through the branch tuned to that component (Fig. 3e). Therefore, mutual isolation between the RF channels is achieved using impedance nodes only.

Isolation using impedance nodes has two major advantages over the schemes based on RF traps. First, a trap is typically designed to block entrance of a particular frequency into another channel. Since mutual isolation for each pair of channels must be achieved, for $n$ channels $n(n-1)$ unwanted pathways must be blocked. For example, for a triple resonance probe, there exist at least $3 \times(3-1)=6$ unwanted electrical pathways. Furthermore, the fact that traps usually affect tuning of all the channels makes it difficult to tune the circuit and establish isolation between the channels at the same time. In contrast, an impedance node prevents leakage of a particular frequency from its own channel to any other channels connected near that node. Thus, the number of unwanted pathways to be blocked is equal to the number of channels and is substantially fewer than in the trap-based design.

The second advantage is related to circuit performance. Due to its lossy nature as a resonator, a trap usually reduces the performance of the channel to which it is tuned, compared to a single resonance circuit. It also affects performance of any other signal flowing through it, although this penalty may be smaller than that for the blocked channel. Even though impedance nodes may not provide ideal isolation, the isolation is passive in the sense that it does not rely on additional lossy resonators. Therefore, the performance penalty for a circuit utilizing impedance nodes is smaller than the penalty for a trap-based circuit.

\subsection{Back propagation of common impedance node}

The overall strategy for building the circuit shown in Fig. 2 involves "back propagation of the common impedance node" with several priorities.

First, we would like to balance the sample coil on all channels. It is known $[34,36]$ that a balanced coil has an impedance node in the middle and vice versa. Therefore, if a common impedance node is set in the middle of the coil, the coil will be simultaneously balanced at all frequencies. In the present case, we balance the circuit by partially symmetrizing it as shown in Fig. 2.

Second, we would like to use another common impedance node for RF isolation, as discussed above. Thus, if we connect all channels to a common junction point and tune a simultaneous impedance node at that junction such that the node points towards the sample coil, electrical isolation between the channels will be achieved. 
Finally, it follows from Fig. 3 and Eq. (2), that any branches connected to a circuit near an impedance node have only a small effect on the behavior of the circuit at the frequency to which the impedance node is tuned. In other words, in accordance with Eq. (2), the impedance at the junction point is $Z_{2}$ and is independent of $Z_{1}$. Accordingly, if a blue impedance node is set at the junction point in the circuit, the blue branch can be tuned with the red branch disconnected. Once the blue branch is tuned and the blue impedance node is set, the red branch can be connected to the blue impedance node with little effect on the node. This modularity is conveniently exploited in the "back propagation of common impedance node" procedure, as illustrated in Fig. 4.

The RF signals enter the circuit through the RF ports (Fig. 2a). The desired electrical path then goes through the sample coil and eventually ends at a corresponding ground point on the right. These target paths can be selected using the previously mentioned property of an impedance node. In order to achieve this goal, each of the three common impedance nodes in Fig. 2 should be tuned by sections of the circuit that are further along the path. Therefore, we shall start tuning the circuit going from the end, i.e. from the ground points where the RF signals leave the circuit (Fig. 4a), and traverse backward towards the RF input ports, while serially adjusting the intervening circuit sections.

Fig. 4a shows the initial state of the circuit before tuning (in gray). The two rightmost sections can be tuned individually (as discussed above) until each presents an impedance node at its respective frequency. Then the two tuned sections can be connected together to form the first common impedance node on the balancing side (Fig. 4b).

The next section (i.e., the preceding section along the RF pathway) is then connected to the previously tuned sections and can be adjusted until the next common impedance node, at the midpoint of the sample coil, is tuned (Fig. 4c). This process is repeated to yield the state in Fig. 4d. Finally, the remaining sections are connected and adjusted until the circuit can be tuned and matched to standard impedance $(50 \Omega)$ as shown in Fig. 4e.

\subsection{Tuning elements}

Each of the blocks in Fig. $2 \mathrm{~b}$ comprises several tuning elements. The symmetry of the overall circuit is such that the two common blocks (black rectangles in Fig. 2b) are structurally identical (comprising the elements in Fig. 6) and the four frequency specific blocks (colored rectangles in Fig. 2b) are structurally similar (comprising the elements in Fig. 5d).

Starting on the balancing side, the first blocks are balancing modules similar to the ones shown in Fig. 5d, except that these balancing modules have a single variable capacitor connected to ground. These blocks tune the first common impedance node. The nodes are first roughly tuned by adjusting the length of the short transmission lines, and then finetuned by adjusting variable capacitors. As discussed below, short sections of transmission line may not transform the ${ }^{13} \mathrm{C}$ impedance efficiently. For this reason, the impedance of the ${ }^{1} \mathrm{H}$ module may not be sufficiently high at low frequencies and may need to be adjusted by adding chip capacitors.

The second section (black right rectangle in Fig. 2b) consists of a coaxial transmission line, a parallel combination of an inductor and ATC chip capacitor in the probe box, and another chip capacitor at the probe top. This section tunes the second common impedance node in the middle of the coil ensuring that the coil is balanced. Since the impedance of this section must be adjusted at multiple frequencies (here, ${ }^{1} \mathrm{H}$ and ${ }^{13} \mathrm{C}$ ), multiple tuning elements are generally necessary. 
Commonly used tuning elements include lumped components, (i.e., capacitors and inductors) and distributed components, such as transmission lines. The effectiveness of these components is frequency dependent. Lumped elements are most efficient at low to medium frequencies, for which the impedance of inductors is not too high and the impedance of capacitors is not too small. At the same time, transmission lines are optimal impedance transformers when the wavelength of the signal approaches the length of the line. As a result, the behaviors of lumped and distributed circuit elements are largely complementary with respect to frequency, and their combination can be used to control all the frequencies as indicated in Fig. 6. Specifically, a variable impedance transmission line is used to transform the ${ }^{1} \mathrm{H}$ impedance. The inner conductor of this line consists of three sections having different diameters (Fig. 5b). This variable impedance transmission line permitted us to reduce the voltage standing wave ratio and the total length of the line.

At the same time, the impedance $Z$ of a parallel combination of an inductor $L$ and a capacitor $C$ is

$$
Z=j \frac{1}{C} \frac{\omega}{\omega_{0}^{2}-\omega^{2}},
$$

where $\omega_{0}$ is the resonant frequency. When frequency $(\omega)$ is lower than the resonant frequency $\left(\omega_{0}\right), Z$ is positive, i.e. inductive, and when frequency is above the resonant frequency, $Z$ is negative, i.e. capacitive. Therefore, as long as $\omega_{0}$ is lower than the ${ }^{13} \mathrm{C}$ frequency and higher than the ${ }^{15} \mathrm{~N}$ frequency (in case of triple resonance circuit), the ${ }^{13} \mathrm{C}$ channel will be more affected by the capacitor while the ${ }^{15} \mathrm{~N}$ channel will be more affected by the inductor.

Finally, tuning modules (Fig. 5d and colored blocks on the left in Fig. 2b), incorporating short sections of coaxial transmission lines and variable capacitors, transform the small node impedance to the standard $50 \Omega$ real impedance. Further technical details are out of the scope of this communication and can be found elsewhere [34].

\section{Experimental verification}

The experimental implementation of the procedures outlined above was divided into several stages. The first stage was the fabrication of a double resonance ${ }^{1} \mathrm{H}$ and ${ }^{13} \mathrm{C}$ static NMR probe, with careful optimization of its circuit and static performance tests. The second stage was conversion of the static probe into a MAS probe with tests under MAS conditions. At this point we did not perform a full circuit optimization, since additional modifications of the probe will be necessary for future cryogenic experiments. Here we report results from the fully optimized static probe and initial MAS results.

\subsection{Static optimized circuit}

A custom double resonance ${ }^{1} \mathrm{H}(500 \mathrm{MHz})$ and ${ }^{13} \mathrm{C}(125 \mathrm{MHz})$ NMR probe, using a 6-turn, $3.2 \mathrm{~mm}$ I.D. solenoid coil, wound out of \#22 silver coated copper wire, and the novel electrical circuit [34,37] schematically represented in Fig. 2 was designed, fabricated and tested on a custom $500 \mathrm{MHz}\left({ }^{1} \mathrm{H}\right)$ NMR spectrometer (courtesy Dr. David J. Ruben). An ETFE tube ( $3.2 \mathrm{~mm}$ O.D.) was center packed $(20 \mu \mathrm{L}$, filling the volume covered by four coil turns) with U- ${ }^{13} \mathrm{C}$-glycerol $\left(100 \%{ }^{13} \mathrm{C}\right)$. Fig. 7 shows the results of nutation experiments and yields $810^{\circ} / 90^{\circ}$ ratios of $86 \%$ for ${ }^{1} \mathrm{H}$ and $89 \%$ for ${ }^{13} \mathrm{C}$, indicating excellent homogeneity on both channels. The high quality of balance on both channels was also verified in profiles of the RF fields (Fig. 8) obtained via a "ball shift test" [32,34,43,44]. This test was performed by accurately positioning a small brass ball $(1.6 \mathrm{~mm}(0.0625 "))$ at different 
positions along the coil axis and recording resonant frequency shifts. Fig. 8 confirms that both profiles are symmetric with a maximum at the center of the coil.

The circuit proved to be robust with respect to salty samples as illustrated by observed Q factors and tunability. Specifically, the $\mathrm{Q}$ factor of the ${ }^{1} \mathrm{H}$ channel dropped from 300 for glycerol to 140 for $0.35 \mathrm{M}$ aqueous solution of $\mathrm{Gdn} \cdot \mathrm{HCl}$ with little change for the ${ }^{13} \mathrm{C}$ channel. While conventional probes often needs to be retuned for samples containing high levels of salt, the present circuit was still tunable even with a sample of $1 \mathrm{M}$ aqueous solution of $\mathrm{NaCl}$.

The probe demonstrated outstanding power performance. With RF isolation between the channels being at least $-50 \mathrm{~dB}$, it generated $\gamma B_{1}=100 \mathrm{kHz}$ for ${ }^{1} \mathrm{H}$ and ${ }^{13} \mathrm{C}$ with just $70 \mathrm{~W}$ and $180 \mathrm{~W}$ of RF input, respectively. The probe also generated $\gamma B_{1}\left({ }^{1} \mathrm{H}\right)=360 \mathrm{kHz}$ at 890 $\mathrm{W}$ and handled prolonged irradiation on both channels $\left(30 \mathrm{~ms}\right.$ of $160 \mathrm{kHz} @{ }^{1} \mathrm{H}$ and $5 \mathrm{~ms}$ of $150 \mathrm{kHz} @{ }^{13} \mathrm{C}$ ) simultaneously without arcing [34]. Fig. 9 shows $\gamma B_{1}$ vs. RF power dependences for both channels (the top two traces). The data conform well to the theoretical dependence [45].

Fig. 9 also illustrates the results of two RF tests. The top blue ${ }^{1}$ trace corresponds to the best RF performance of the ${ }^{1} \mathrm{H}$ channel obtained after carefully optimizing the circuit for good balance (Fig. 8) and ensuring that all components and connections had high mechanical and electrical quality. The bottom blue trace shows the result of an intermediate test. While the latter is comparable to performance of a commercial probe (a locally tuned Varian $\mathrm{HCN}$ probe with a $4 \mathrm{~mm}$ solenoid), the optimized circuit generates the same $\gamma B_{1}\left({ }^{1} \mathrm{H}\right)$ using 4fold less RF power. Although the efficiency of the ${ }^{13} \mathrm{C}$ channel (data not shown) was also better for the optimized circuit, the improvement was substantially smaller than for the ${ }^{1} \mathrm{H}$ channel.

\subsection{MAS tests}

The performance of the probe equipped with a MAS stator was found to be comparable to that of the static probe. The probe efficiency decreased slightly, due to the fact that the sample coil in the MAS stator is inclined at the magic angle with respect to the static field, as opposed to $90^{\circ}$ in the case of a static probe. In order to evaluate the robustness and longterm stability of the probe, we acquired 2D correlation spectra for a model microcrystalline peptide and a hydrated protein.

The peptide, N-formyl-[U- $\left.{ }^{13} \mathrm{C},{ }^{15} \mathrm{~N}\right]-$ Met-Leu-Phe-OH (N-f-MLF-OH) was prepared as described previously [46] and used for testing MAS stability and the performance of multipulse ${ }^{1} \mathrm{H}$ decoupling and ${ }^{13} \mathrm{C}$ dipolar recoupling. Stable spinning at $12.5 \mathrm{kHz}( \pm 5 \mathrm{~Hz})$ was maintained throughout the experiments (6 days). Fig. 10a shows $2 \mathrm{D}{ }^{13} \mathrm{C}-{ }^{13} \mathrm{C}$ correlation spectra of N-f-MLF-OH using RFDR recoupling in a broadband fashion [47-50]. Recoupling times of $1.3 \mathrm{~ms}$ and $9.3 \mathrm{~ms}$ were used for one-bond (red) and multi-bond (black) correlations, respectively. The 1D cross polarization (CP) spectrum of MLF (data not shown) indicates a ${ }^{13} \mathrm{C}$ linewidth of $24 \mathrm{~Hz}$ for the methyl carbon of Met $\mathrm{C} \delta$ at $14.0 \mathrm{ppm}$ (referenced to TMS), suggesting efficient ${ }^{1} \mathrm{H}$ TPPM decoupling [51]. The one-bond correlation spectrum contains well-resolved cross peaks of directly bonded carbon spins, indicating the high efficiency of the RFDR mixing scheme. At a longer mixing time of 9.3 $\mathrm{ms}$, multi-bond intra- and inter-residue correlations appear, indicating consistently efficient ${ }^{1} \mathrm{H}$ decoupling.

\footnotetext{
${ }^{1}$ For interpretation of color in Figs. 7-10, the reader is referred to the web version of this article.
} 
To further test the probe performance for hydrated protein samples, a 2D one-bond RFDR experiment (Fig. 10b) was carried out using a PI3-SH3 fibril sample. 50\% hydration (w/w) was achieved by using a $60 / 40(\mathrm{w} / \mathrm{w})$ mixture of $d 5$-glycerol and buffer $(\mathrm{pH}=2.0)$. The line width is $0.5-0.8 \mathrm{ppm}(62.5-100 \mathrm{~Hz})$. The single set of chemical shifts and excellent linewidth reveal the high degree of sample homogeneity. Overall, the spectrum compares favorably with our previous studies of PI3-SH3 [52], in terms of the number of cross peaks, resolution, intensities and linewidths, suggesting efficient recoupling and strong circuit performance.

\section{Conclusions and outlook}

We presented an efficient new strategy for designing fully balanced transmission line RF circuits for MAS probes based on back propagation of common impedance nodes. This strategy was illustrated using a custom double resonance $\left({ }^{1} \mathrm{H},{ }^{13} \mathrm{C}\right) 3.2 \mathrm{~mm}$ NMR probe. With high quality implementation, BPCIN yielded a RF circuit that demonstrated outstanding RF field characteristics $\left(810^{\circ} / 90^{\circ}\right.$ ratios of $86 \%$ for ${ }^{1} \mathrm{H}$ and $89 \%$ for ${ }^{13} \mathrm{C} ; \gamma B_{1}=$ $100 \mathrm{kHz}$ for ${ }^{1} \mathrm{H}$ and ${ }^{13} \mathrm{C}$ at $70 \mathrm{~W}$ and $180 \mathrm{~W}$ of RF input, respectively, and up to $360 \mathrm{kHz}$ for ${ }^{1} \mathrm{H}$ ). 2D MAS correlation spectra confirmed the robust performance of the probe, which is critical for long-term signal averaging in studies of biological samples. A triple resonance probe based on the same design is under construction.

This paper is addressed to the broad NMR community. More technical details are available in Refs. [34,37] and a theoretical analysis of the observed performance of the circuit will be the subject of a forthcoming publication (Markhasin et al., [53]).

\section{Acknowledgments}

This research was supported by the National Institutes of Health through Grants EB003151, EB002026, EB001960, and EB001035. We thank Michael Mullins and Ajay Thakkar, for crucial assistance with construction of the probe.

\section{References}

[1]. Renault M, Cukkemane A, Baldus M. Solid-state NMR spectroscopy on complex biomolecules. Angew. Chem., Int. Ed. 2010; 49:8346-8357.

[2]. Lesage A. Recent advances in solid-state NMR spectroscopy of spin I = 1/2 nuclei. Phys. Chem. Chem. Phys. 2009; 11:6876-6891. [PubMed: 19652822]

[3]. Andronesi OC, von Bergen M, Biernat J, Seidel K, Griesinger C, Mandelkow E, Baldus M. Characterization of Alzheimer's-like paired helical filaments from the core domain of tau protein using solid-state NMR spectroscopy. J. Am. Chem. Soc. 2008; 130:5922-5928. [PubMed: 18386894]

[4]. Etzkorn M, Boeckmann A, Lange A, Baldus M. Probing molecular interfaces using 2D magicangle-spinning NMR on protein mixtures with different uniform labeling. J. Am. Chem. Soc. 2004; 126:14746-14751. [PubMed: 15535698]

[5]. Lange A, Becker S, Seidel K, Giller K, Pongs O, Baldus M. A concept for rapid protein-structure determination by solid-state NMR spectroscopy. Angew. Chem., Int. Ed. 2005; 44:2089-2092.

[6]. Cady SD, Schmidt-Rohr K, Wang J, Soto CS, De Grado WF, Hong M. Structure of the amantadine binding site of influenza M2 proton channels in lipid bilayers. Nature (London, UK). 2010; 463:689-692. [PubMed: 20130653]

[7]. Griffin RG. Dipolar recoupling in MAS spectra of biological solids. Nat. Struct. Biol. 1998; 5:508-512. [PubMed: 9665180]

[8]. Mak-Jurkauskas ML, Bajaj VS, Hornstein MK, Belenky M, Griffin RG, Herzfeld J. Energy transformations early in the bacteriorhodopsin photocycle revealed by DNP-enhanced solid-state NMR. Proc. Natl. Acad. Sci. USA. 2008; 105:883. [PubMed: 18195364] 
[9]. Castellani F, van Rossum B-J, Diehl A, Rehbein K, Oschkinat H. Determination of solid-state NMR structures of proteins by means of three-dimensional $15 \mathrm{~N}-13 \mathrm{C}-13 \mathrm{C}$ dipolar correlation spectroscopy and chemical shift analysis. Biochemistry (NY). 2003; 42:11476.

[10]. Hong M, Su Y. Structure and dynamics of cationic membrane peptides and proteins: insights from solid-state NMR. Protein Sci. 2011; 20:641-655. [PubMed: 21344534]

[11]. Brown SP, Spiess HW. Advanced solid-state NMR methods for the elucidation of structure and dynamics of molecular, macromolecular, and supramolecular systems. Chem. Rev. (Washington, DC). 2001; 101:4125-4155.

[12]. Ladizhansky, V. Encyclopedia of Magnetic Resonance. John Wiley \& Sons, Ltd.; 2007. DipolarBased Torsion Angle Measurements for Protein Structure Determination.

[13]. De Paepe G, Lewandowski JR, Loquet A, Boeckmann A, Griffin RG. Proton assisted recoupling and protein structure determination. J. Chem. Phys. 2008; 129:245101/1-245101/21. [PubMed: 19123534]

[14]. Barnes AB, Andreas LB, Huber M, Ramachandran R, van der Wel PCA, Veshtort M, Griffin RG, Mehta MA. High-resolution solid-state NMR structure of alanyl-prolyl-glycine. J. Magn. Reson. 2009; 200:95-100. [PubMed: 19596601]

[15]. Van der Wel PCA, Lewandowski JR, Griffin RG. Solid-state NMR study of amyloid nanocrystals and fibrils formed by the peptide GNNQQNY from yeast prion protein Sup35p. J. Am. Chem. Soc. 2007; 129:5117. [PubMed: 17397156]

[16]. Tycko R. Biomolecular solid state NMR: advances in structural methodology and applications to peptide and protein fibrils. Annu. Rev. Phys. Chem. 2001; 52:575-606. [PubMed: 11326075]

[17]. Frydman L. Spin-1/2 and beyond. A perspective in solid state NMR spectroscopy. Annu. Rev. Phys. Chem. 2001; 52:463. [PubMed: 11326072]

[18]. Christopher, V. Grant; Chin, H. Wu; Stanley, J. Opella Probes for high field solid-state NMR of lossy biological samples. J. Magn. Reson. 2010; 204:180-188. [PubMed: 20435493]

[19]. McKay, RA. Encyclopedia of Magnetic Resonance. John Wiley \& Sons, Ltd.; 2007. Probes for Special Purposes.

[20]. Schaefer, J.; Mckay, RA. Multi-tuned Single Coil Transmission Line Probe for Nuclear Magnetic Resonance Spectrometer. Patent. \#5861748. 1999.

[21]. Gor'kov, PL.; Brey, WW.; Long, JR. Encyclopedia of Magnetic Resonance. John Wiley \& Sons, Ltd.; 2007. Probe Development for Biosolids NMR Spectroscopy.

[22]. Barnes, AB.; Mak-Jurkauskas, ML.; Markhasin, E.; Hu, J.; Matsuki, Y.; Lugtenburg, J.; Herzfeld, J.; Griffin, RG. Magnetic Resonance Gordon Research Conference. University of New England; Biddeford, ME: 2009. Instrumentation for Cryogenic MAS and High-Field Dynamic Nuclear Polarization.

[23]. Barnes AB, Markhasin E, Daviso E, Michaelis VK, Nanni EA, Jawla SK, Mena EL, DeRocher R, Thakkar A, Woskov PP, Herzfeld J, Temkin RJ, Griffin RG. Dynamic nuclear polarization at 700 MHz/460 GHz. J. Magn. Reson. 2012; 224:1-7. [PubMed: 23000974]

[24]. Barnes AB, Mak-Jurkauskas ML, Matsuki Y, Bajaj VS, van der Wel PCA, De Rocher R, Bryant J, Sirigiri JR, Temkin RJ, Lugtenburg J, Herzfeld J, Griffin RG. Cryogenic sample exchange NMR probe for magic angle spinning dynamic nuclear polarization. J. Magn. Reson. 2009; 198:261-270. [PubMed: 19356957]

[25]. Barnes AB, De Paepe G, van der Wel PCA, Hu KN, Joo CG, Bajaj VS, Mak-Jurkauskas ML, Sirigiri JR, Herzfeld J, Temkin RJ, Griffin RG. High-field dynamic nuclear polarization for solid and solution biological NMR. Appl. Magn. Reson. 2008; 34:237-263. [PubMed: 19194532]

[26]. Van der Wel PCA, Hu K-N, Lewandowski J, Griffin RG. Dynamic nuclear polarization of amyloidogenic peptide nanocrystals: GNNQQNY, a core segment of the yeast prion protein Sup35p. J. Am. Chem. Soc. 2006; 128:10840-10846. [PubMed: 16910679]

[27]. Maly T, Debelouchina GT, Bajaj VS, Hu K-N, Joo C-G, Mak-Jurkauskas ML, Sirigiri JR, van der Wel PCA, Herzfeld J, Temkin RJ, Griffin RG. Dynamic nuclear polarization at high magnetic fields. J. Chem. Phys. 2008; 128:052211/1. [PubMed: 18266416]

[28]. Debelouchina GT, Bayro MJ, van der Wel PCA, Caporini MA, Barnes AB, Rosay M, Maas WE, Griffin RG. Dynamic nuclear polarization-enhanced solid-state NMR spectroscopy of 
GNNQQNY nanocrystals and amyloid fibrils. Phys. Chem. Chem. Phys. 2010; 12:5911-5919. [PubMed: 20454733]

[29]. Bajaj VS, van der Wel PCA, Griffin RG. Observation of a low-temperature, dynamically driven structural transition in a polypeptide by solid-State NMR spectroscopy. J. Am. Chem. Soc. 2009; 131:118-128. [PubMed: 19067520]

[30]. Lesage A, Lelli M, Gajan D, Caporini MA, Vitzthum V, Mieville P, Alauzun J, Roussey A, Thieuleux C, Mehdi A, Bodenhausen G, Coperet C, Emsley L. Surface enhanced NMR spectroscopy by dynamic nuclear polarization. J. Am. Chem. Soc. 2010; 132:15459-15461. [PubMed: 20831165]

[31]. Vitzthum V, Mieville P, Carnevale D, Caporini MA, Gajan D, Coperet C, Lelli M, Zagdoun A, Rossini AJ, Lesage A, Emsley L, Bodenhausen G. Dynamic nuclear polarization of quadrupolar nuclei using cross polarization from protons: surface-enhanced aluminium-27 NMR. Chem. Commun. (Cambridge, United Kingdom). 2012; 48:1988-1990.

[32]. Paulson EK, Martin RW, Zilm KW. Cross polarization, radio frequency field homogeneity, and circuit balancing in high field solid state NMR probes. J. Magn. Reson. 2004; 171:314. [PubMed: 15546758]

[33]. Hu, J.; Bielecki, A.; Griffin, RG.; Herzfeld, J. A Totally Balanced, Fully Transmission Line, Triple Resonance NMR Probe for High Frequencies, 49th ENC. Pacific Grove; California: 2008.

[34]. Hu, J. Ph.D. Thesis. Brandeis University; 2010. Balanced Multi-resonant Transmission Line Nuclear Magnetic Resonance Probes; p. 471<http://search.proquest.com/docview/305185343/ abstract>

[35]. Mispelter, J.; Lupu, M.; Briguet, A. NMR Probeheads for Biophysical and Biomedical Experiments: Theoretical Principles \& Practical Guidelines. Imperial College Press; London, Hackensack, NJ: 2006. Distributed by World Scientific

[36]. Engelke F. Electromagnetic wave compression and radio frequency homogeneity in NMR solenoidal coils: computational approach. Concepts Magn. Reson. 2002; 15:129.

[37]. Hu, J.; Herzfeld, J. Baluns, A Fine Balance and Impedance Adjustment Module, A Multi-Layer Transmission Line, and Transmission Line NMR Probes Using Same. Patent. \#7936171. 2011.

[38]. Schnall MD, Subramanian VH, Leigh JS Jr. Chance B. A new double-tuned probe for concurrent proton and phosphorus-31 NMR. J. Magn. Reson. (1969-1992). 1985; 65:122-129.

[39]. Stoll ME, Vega AJ, Vaughn RW. Simple single-coil double resonance NMR probe for solid state studies. Rev. Sci. Instrum. 1977; 48:800-803.

[40]. Cross VR, Hester RK, Waugh JS. Single coil probe with transmission-line tuning for nuclear magnetic double resonance. Rev. Sci. Instrum. 1976; 47:1486-1488.

[41]. Doty FD, Inners RR, Ellis PD. A multinuclear double-tuned probe for applications with solids or liquids utilizing lumped tuning elements. J. Magn. Reson. (1969-1992). 1981; 43:399-416.

[42]. McKay, RA. Double-tuned Single Coil Probe for Nuclear Magnetic Resonance Spectrometer. Patent. \#4446431. 1984.

[43]. Maier JLC, Slater JC. Field strength measurements in resonant cavities. J. Appl. Phys. 1952; 23:68-77.

[44]. Maier JLC, Slater JC. Determination of field strength in a linear accelerator cavity. J. Appl. Phys. $1952 ; 23: 78-83$.

[45]. Doty, FD. Encyclopedia of Magnetic Resonance. John Wiley \& Sons, Ltd.; 2007. Probe Design and Construction.

[46]. Rienstra CM, Tucker-Kellogg L, Jaroniec CP, Hohwy M, Reif B, McMahon MT, Tidor B, Lozano-Perez T, Griffin RG. De novo determination of peptide structure with solid-state magicangle spinning NMR spectroscopy. Proc. Natl. Acad. Sci. USA. 2002; 99:10260-10265. [PubMed: 12149447]

[47]. Bennett AE, Ok JH, Griffin RG, Vega S. Chemical shift correlation spectroscopy in rotating solids: radio frequency-driven dipolar recoupling and longitudinal exchange. J. Chem. Phys. 1992; 96:8624.

[48]. Bayro MJ, Ramachandran R, Caporini MA, Eddy MT, Griffin RG. Radio frequency-driven recoupling at high magic-angle spinning frequencies: Homonuclear recoupling sans heteronuclear decoupling. J. Chem. Phys. 2008; 128:052321/1. [PubMed: 18266438] 
[49]. Bennett AE, Rienstra CM, Griffiths JM, Zhen W, Lansbury PT Jr. Griffin RG. Homonuclear radio frequency-driven recoupling in rotating solids. J. Chem. Phys. 1998; 108:9463.

[50]. Boender GJ, Vega S, de Groot HJM. Quantized field description of rotor frequency-driven dipolar recoupling. J. Chem. Phys. 2000; 112:1096-1106.

[51]. Bennett AE, Rienstra CM, Auger M, Lakshmi KV, Griffin RG. Heteronuclear decoupling in rotating solids. J. Chem. Phys. 1995; 103:6951.

[52]. Bayro MJ, Debelouchina GT, Eddy MT, Birkett NR, MacPhee CE, Rosay M, Maas WE, Dobson CM, Griffin RG. Intermolecular structure determination of amyloid fibrils with magic-angle spinning and dynamic nuclear polarization NMR. J. Am. Chem. Soc. 2011; 133:13967-13974. [PubMed: 21774549]

[53]. Markhasin, E., et al. in preparation 
(a)

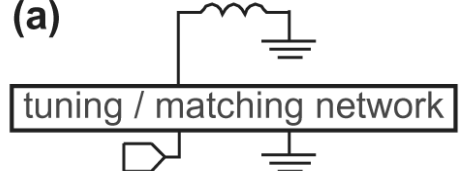

(b)

tuning / matching network

Fig. 1.

Schematic of a RF circuit with (a) a common mode input and (b) balanced input. 




Fig. 2.

(a) Simplified schematic and (b) block diagram of a balanced double resonance RF circuit $[34,37]$. Red and blue colors indicate two different working frequencies. Black dots $(\bullet)$ indicate positions of common impedance nodes. Each impedance node is tuned by a circuit section that is further along the electrical pathway (on the right) and propagates the signal through that section. (For interpretation of the references to color in this figure legend, the reader is referred to the web version of this article.) 
(a)

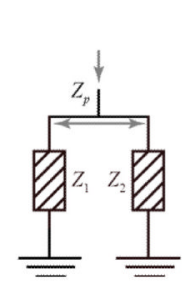

(b)



(c)

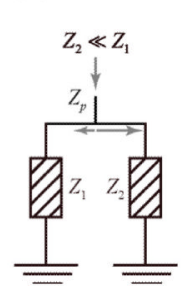

(d)

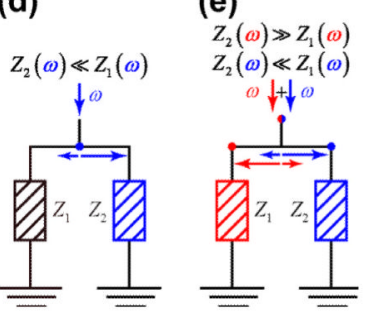

Fig. 3.

Mutual isolation of multiple RF channels by means of a common impedance node. The locations of impedance nodes are indicated with colored dots. (For interpretation of the references to color in this figure legend, the reader is referred to the web version of this article.) 


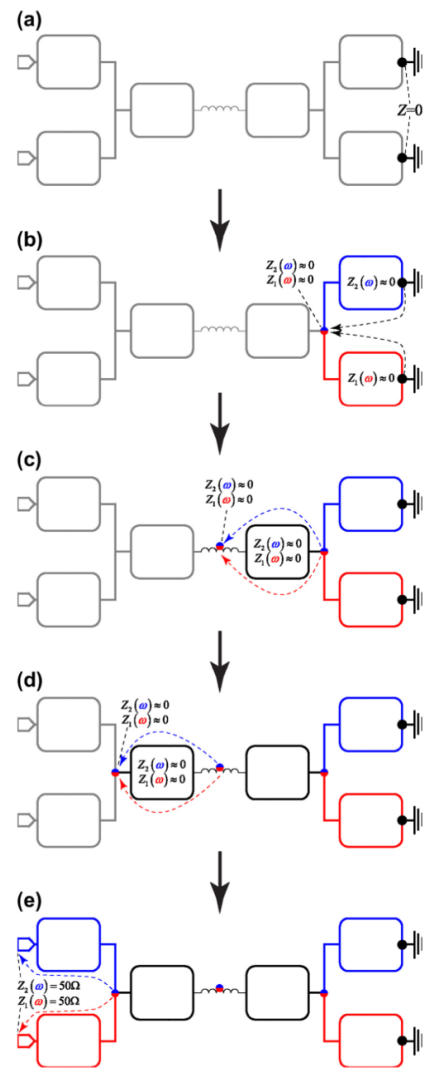

Fig. 4.

Diagram showing stepwise propagation of common impedance nodes along the circuit. Gray color indicates circuit blocks that have not yet been tuned. Dots indicate locations of common impedance nodes for two frequencies (red and blue) and the ends of RF paths (black). (For interpretation of the references to color in this figure legend, the reader is referred to the web version of this article.) 


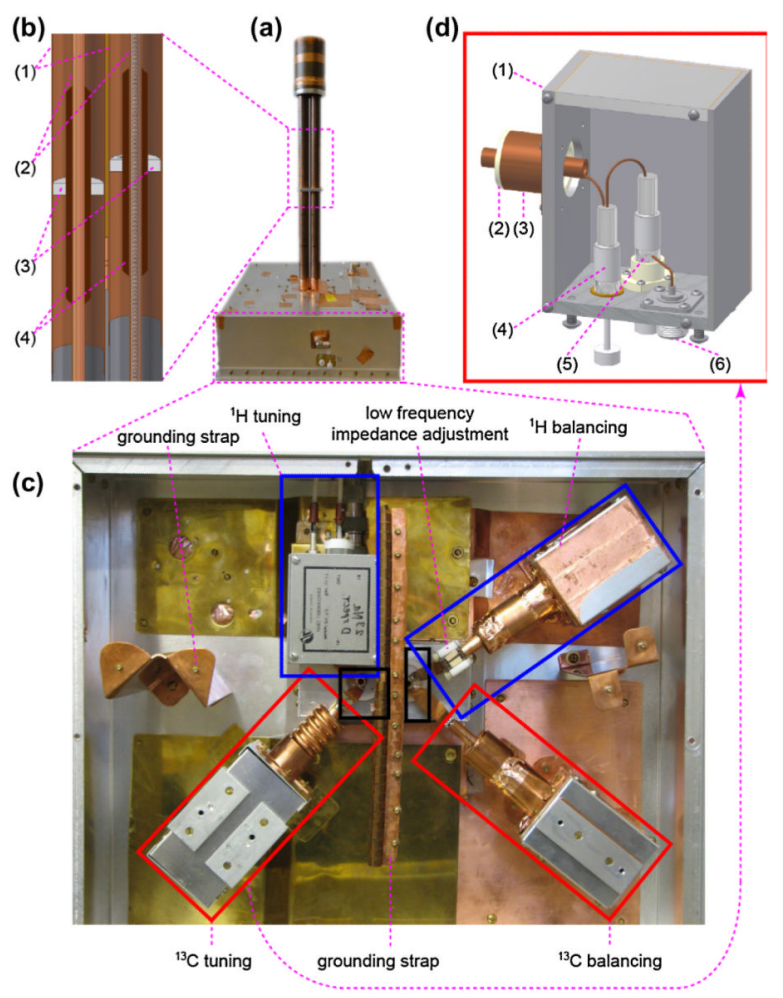

Fig. 5.

Implementation of ${ }^{1} \mathrm{H}(500 \mathrm{MHz}),{ }^{13} \mathrm{C}(125 \mathrm{MHz})$ fully balanced, transmission line probe. (a) Photograph of the probe. (b) 3D CAD cutaway view of a section of main coaxial transmission lines with (1) outer conductors, Cu tube, $2.858 \mathrm{~cm}(1.125$ ”) O.D. and $2.680 \mathrm{~cm}$ (1.055”) I.D., (2) compound inner conductors, consisting of two sections, $\mathrm{Cu}, 0.953 \mathrm{~cm}$ (0.375”) O.D. and OFHC Cu, $0.635 \mathrm{~cm}$ (0.25”) O.D., (3) PTFE spacer, (4) large O.D. inner conductor ("sausage"), $\mathrm{Cu}, 0.19 \mathrm{~cm}(0.75$ ") O.D. (c) Photograph of probe box with colored rectangles identifying parts corresponding to the colored blocks in Fig. 2b. (d) 3D CAD view of a tuning/matching module showing (1) aluminum casing, (2) PTFE spacer, (3) short coaxial transmission line, $\mathrm{Cu}$ tubes, $2.858 \mathrm{~cm}(1.125$ ”) O.D. and $0.953 \mathrm{~cm}(0.375$ ") O.D. and $2.680 \mathrm{~cm}$ (1.055”) I.D., (4) variable tuning capacitor (Polyflon), (5) variable matching capacitor (Polyflon), (6) RF port. Original design and construction by $\mathrm{Hu}[34,37]$. (For interpretation of the references to color in this figure legend, the reader is referred to the web version of this article.) 


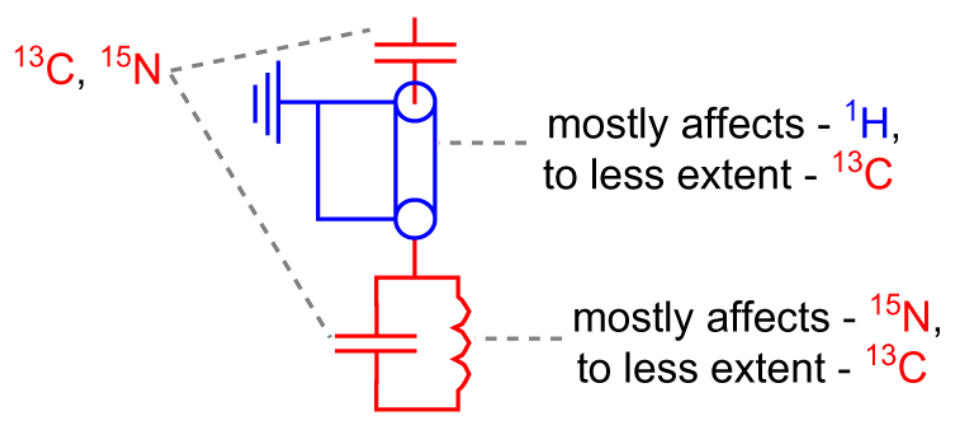

Fig. 6.

Schematic indicating the function of the tuning elements that form the common (black) blocks in Fig. 2b. The same elements are used in both double and triple resonance configurations. 


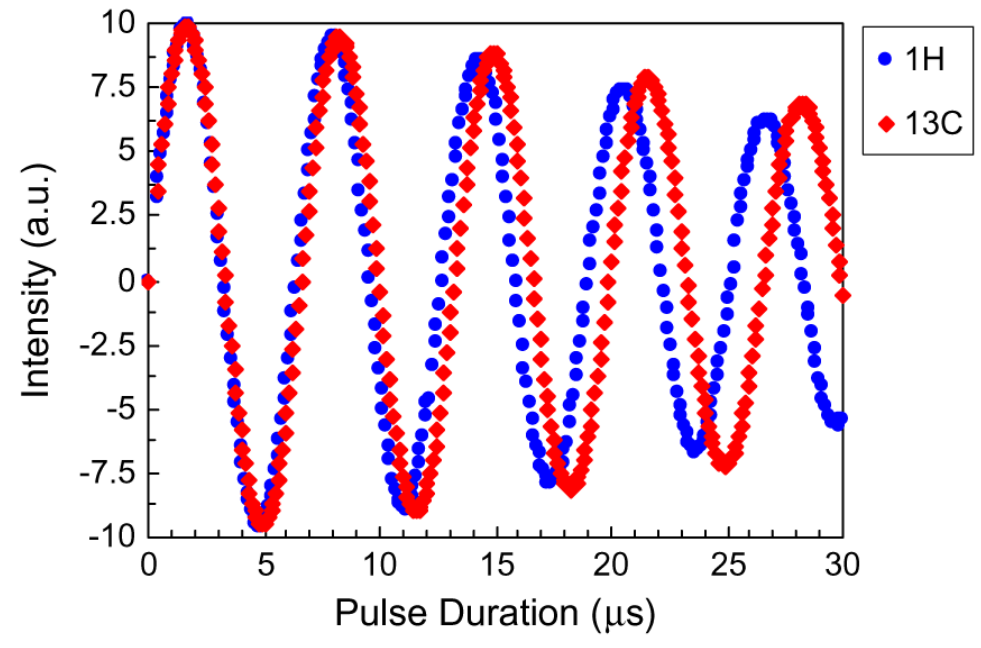

Fig. 7.

${ }^{1} \mathrm{H}$ and ${ }^{13} \mathrm{C}$ nutation curves [34]. 


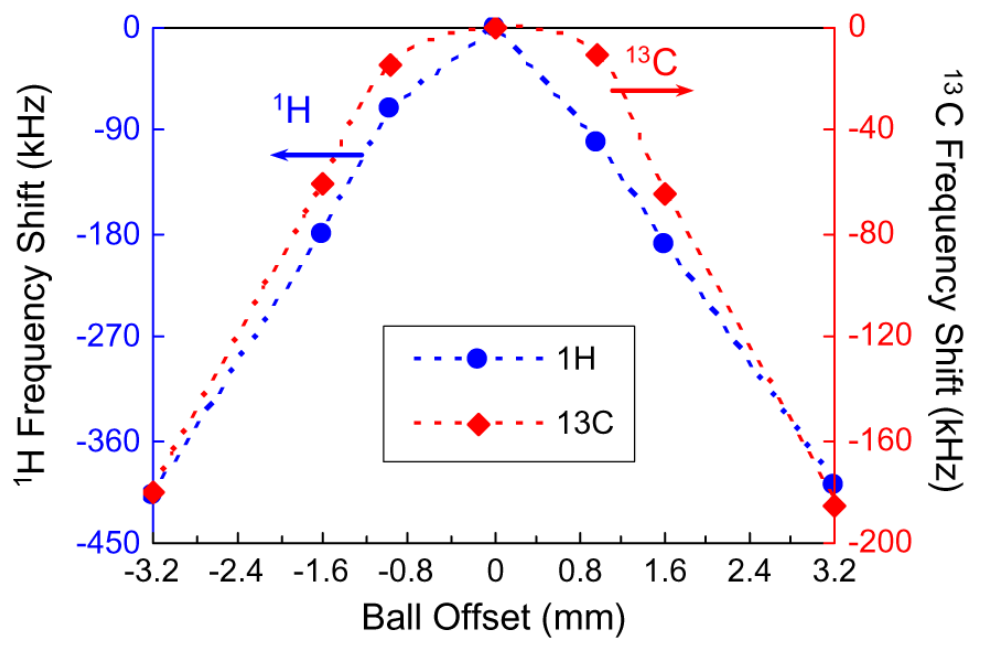

Fig. 8.

${ }^{1} \mathrm{H}$ and ${ }^{13} \mathrm{C}$ balance a ball shift test [34]. 


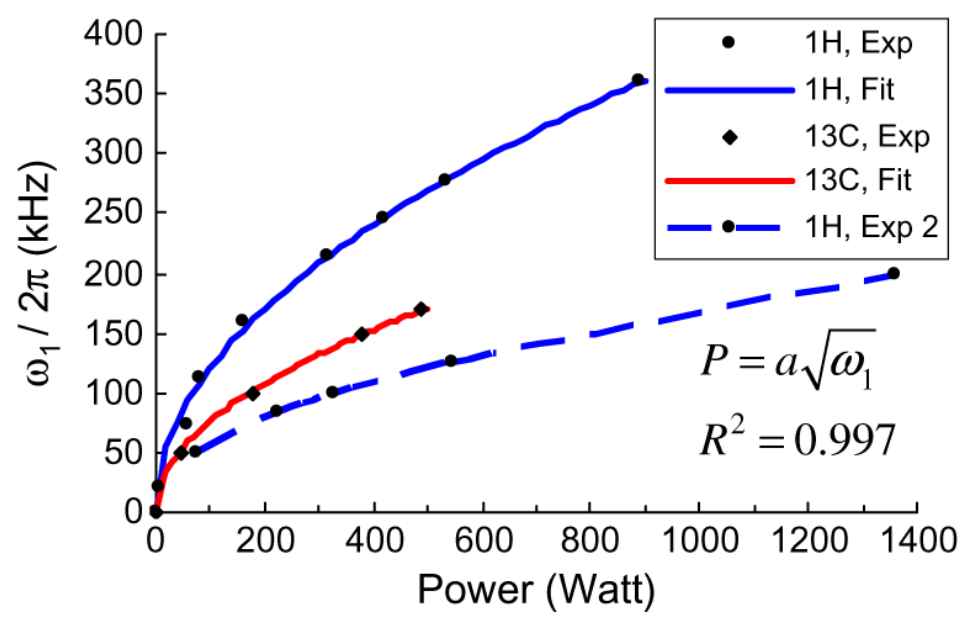

Fig. 9.

${ }^{1} \mathrm{H}$ and ${ }^{13} \mathrm{C} \gamma B_{1}$ dependence on input RF power [34]. 

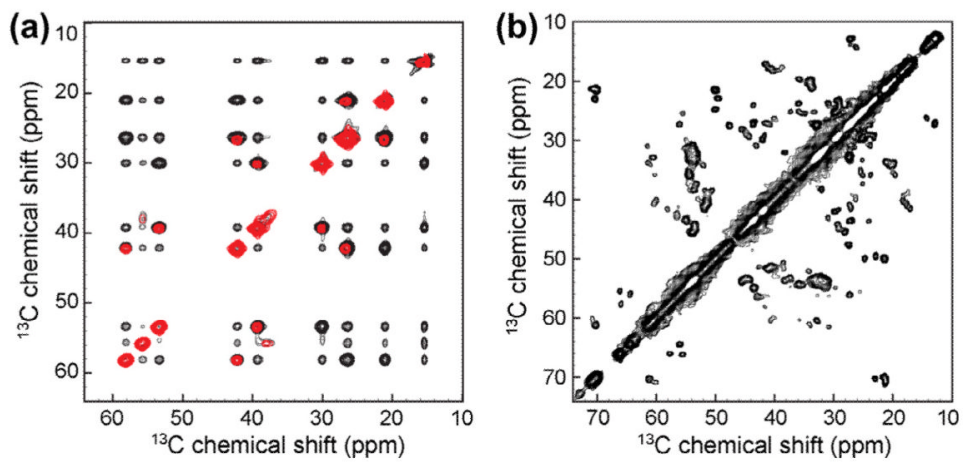

Fig. 10.

Broadband RFDR [47-50] spectra of uniformly ${ }^{13} \mathrm{C}$ and ${ }^{15} \mathrm{~N}$ labeled peptide and protein samples. (a) N-f-MLF and (b) PI3-SH3 fibrils. All spectra were acquired at $\omega_{\mathrm{r}} / 2 \pi=12.5$ $\mathrm{kHz}$ MAS frequency and at room temperature. A rotor-synchronized $33 \mathrm{kHz}{ }^{13} \mathrm{C} \pi$-pulses were used during the RFDR mixing period in all experiments. The ${ }^{1} \mathrm{H}$ TPPM [51] decoupling field of $100 \mathrm{kHz}$ was applied during mixing and acquisition periods. 